\title{
Acute regadenoson stress prefusion testing using cardiac MRI is a valuable test of high predictive value for risk stratification of COPD-patients with NSTEM
}

Felix T Range*, Florian Bönner, Sebastian M Haberkorn, Dirk Dinjus, Stefanie Keymel, Malte Kelm, Mirja Neizel-Wittke

From 19th Annual SCMR Scientific Sessions

Los Angeles, CA, USA. 27-30 January 2016

\section{Background}

The diagnostic dilemma of patients suffering from chronic obstructive pulmonary disease (COPD) presenting with symptoms equivalent to an acute coronary syndrome (ACS) and slightly elevated high sensitive troponine in the observational range (hsTnT 14-53 ng/l) is complex. Prognostic impact of elevated hsTnT demand further investigation. Comorbidities of COPD and coronary artery disease are frequent, risk factors congruent. The acute setting demands a safe and easily conductible test to identify coronary problems reliably. Echocardiographic imaging quality is often low due to emphysema. Adenosine is contraindicated due to its bronchospasmic effect. The new vasodilatator regadenoson does not bear this limitation.

This study aims to evaluate feasibility and prognostic power of regadenoson stress cMRI in the above described population.

\section{Methods}

Twenty-two patients $(70 \pm 13$ yo) with COPD GOLD grade I-III presenting with ACS and elevated hsTnT in the observational range $(23 \pm 9 \mathrm{ng} / \mathrm{l})$ were enrolled. Prior to coronary catheterization, they underwent cMRI with regadenoson-stress (400 $\mu$ g i.v. bolus). Scans were conducted on a Philips Achieva 1.5 T MRI, including CINEsequences, T2-imaging, late enhancement imaging, pulmonary angiography as well as rest and stress myocardial perfusion measurements. All Patients received pulmonary

\footnotetext{
Dept. of Cardiology, Pneumology and Angiology, University hospital of
} Düsseldorf, Neuss, Germany

\section{Results}

No adverse effect of regadenoson was observed. Pulmonary function testing revealed a slight but not significant amelioration after regadenoson (FEV1 pre and post MRI: $67 \%$ and $73 \%, \mathrm{p}=\mathrm{ns}$ ).

Quality of the scans remained unhampered by the emergency management. All scans were conducted within 48 hours after presentation, also allowing consecutive coronary catheterization within this time frame. Regadenoson elevated heart rate and rate-pressure-product significantly by $30 \%$. In eight patients, stress cMRI detected myocardial in all these patients, coronary catheterization ealed relevant coronary stenoses necessitating intervenIn all cases, the respective vessel was correctly prevected no myocardial ischemia, coronary catheterrevealed no coronary stenosis. We found positiv stress at $100 \%$ in our population.

\section{Conclusions}

Cardiac stress MRI proved safe, feasible in a limited timeframe and of high predictive accuracy in our study. Regadenoson did not deteriorate pulmonary function. The quality of cMRI scans and analysis did not suffer from the emergency setting and positive and negative predictive values were $100 \%$ when determining the need 
for coronary revascularisation and predicting the target vessel.

This method is ready to be implemented in a differentiated management of patients with COPD and slightly elevated hsTnT.

Published: 27 January 2016

doi:10.1186/1532-429X-18-S1-P105

Cite this article as: Range et al:: Acute regadenoson stress prefusion testing using cardiac MRI is a valuable test of high predictive value for risk stratification of COPD-patients with NSTEM. Journal of Cardiovascular Magnetic Resonance 2016 18(Suppl 1):P105.

Submit your next manuscript to BioMed Central and take full advantage of:

- Convenient online submission

- Thorough peer review

- No space constraints or color figure charges

- Immediate publication on acceptance

- Inclusion in PubMed, CAS, Scopus and Google Scholar

- Research which is freely available for redistribution

Submit your manuscript at www.biomedcentral.com/submit 